\title{
Overexpression of vesicle-associated membrane protein PttVAP27-17 as a tool to improve biomass production and the overall saccharification yields in Populus trees
}

Madhavi Latha Gandla', Niklas Mähler², Sacha Escamez ${ }^{2,3}$, Tomas Skotare ${ }^{1,6}$, Ogonna Obudulu ${ }^{3,7}$, Linus Möller ${ }^{4}$, Ilka N. Abreu ${ }^{3}$, Joakim Bygdell ${ }^{1}$, Magnus Hertzberg ${ }^{4}$, Torgeir R. Hvidsten², ${ }^{2,}$ Thomas Moritz ${ }^{3}$, Gunnar Wingsle ${ }^{3}$, Johan Trygg ${ }^{1,6}$, Hannele Tuominen ${ }^{2,8^{*}}$ (D) and Leif J. Jönsson ${ }^{1}$

\begin{abstract}
Background: Bioconversion of wood into bioproducts and biofuels is hindered by the recalcitrance of woody raw material to bioprocesses such as enzymatic saccharification. Targeted modification of the chemical composition of the feedstock can improve saccharification but this gain is often abrogated by concomitant reduction in tree growth.

Results: In this study, we report on transgenic hybrid aspen (Populus tremula $\times$ tremuloides) lines that showed potential to increase biomass production both in the greenhouse and after 5 years of growth in the field. The transgenic lines carried an overexpression construct for Populus tremula $\times$ tremuloides vesicle-associated membrane protein (VAMP)-associated protein PttVAP27-17 that was selected from a gene-mining program for novel regulators of wood formation. Analytical-scale enzymatic saccharification without any pretreatment revealed for all greenhouse-grown transgenic lines, compared to the wild type, a $20-44 \%$ increase in the glucose yield per dry weight after enzymatic saccharification, even though it was statistically significant only for one line. The glucose yield after enzymatic saccharification with a prior hydrothermal pretreatment step with sulfuric acid was not increased in the greenhousegrown transgenic trees on a dry-weight basis, but increased by $26-50 \%$ when calculated on a whole biomass basis in comparison to the wild-type control. Tendencies to increased glucose yields by up to $24 \%$ were present on a whole tree biomass basis after acidic pretreatment and enzymatic saccharification also in the transgenic trees grown for 5 years on the field when compared to the wild-type control.

Conclusions: The results demonstrate the usefulness of gene-mining programs to identify novel genes with the potential to improve biofuel production in tree biotechnology programs. Furthermore, multi-omic analyses, including transcriptomic, proteomic and metabolomic analyses, performed here provide a toolbox for future studies on the function of VAP27 proteins in plants.
\end{abstract}

Keywords: Populus, Vesicle-associated membrane protein, VAMP, VAMP-associated protein, VAP27, Growth, Bioprocessing, Transcriptomics, Proteomics, Metabolomics

*Correspondence: hannele.tuominen@slu.se

2 Umeå Plant Science Centre, Department of Plant Physiology, Umeå University, 90187 Umeå, Sweden

Full list of author information is available at the end of the article

\section{Background}

Wood and other lignocellulosic feedstocks can serve as an abundant renewable source of sugars and other platform molecules for the production of advanced biofuels, green chemicals, and bio-based materials. One way

c) The Author(s) 2021. This article is licensed under a Creative Commons Attribution 4.0 International License, which permits use, sharing, adaptation, distribution and reproduction in any medium or format, as long as you give appropriate credit to the original author(s) and the source, provide a link to the Creative Commons licence, and indicate if changes were made. The images or other third party material in this article are included in the article's Creative Commons licence, unless indicated otherwise in a credit line to the material. If material is not included in the article's Creative Commons licence and your intended use is not permitted by statutory regulation or exceeds the permitted use, you will need to obtain permission directly from the copyright holder. To view a copy of this licence, visit http://creativeco mmons.org/licenses/by/4.0/. The Creative Commons Public Domain Dedication waiver (http://creativecommons.org/publicdomain/ zero/1.0/) applies to the data made available in this article, unless otherwise stated in a credit line to the data. 
to deconstruct the biomass is through pretreatment and enzymatic saccharification, which results in the release of sugars from cellulose and hemicelluloses [1, 2]. In this process, the major challenge is the recalcitrance of the biomass mainly due to prevention of access of enzymes to cellulose by hemicelluloses and lignin, high degree of cellulose polymerization, covalent cross-linkages between lignin and hemicelluloses, and other factors that remain to be determined $[1,3,4]$. Although wood is rather well characterized chemically and anatomically, the knowledge on genetic pathways that could be manipulated to reduce feedstock recalcitrance without compromising the properties and formation of wood is still scarce [5-7]. Identification of novel genes and/or pathways that control wood properties and growth of trees, therefore, provides a foundation not only for genetic improvement of the quality and quantity of wood, but also for improved saccharification efficiency and convertibility of woody biomass.

Numerous initiatives have been taken to improve saccharification in forest feedstocks by transgenic means. The most commonly studied species belong to the Populus family, including poplar and aspen trees. Advantages of Populus trees include their high biomass production rate $\left(25 \mathrm{Mg} \mathrm{ha}^{-1}\right.$ year $\left.^{-1}\right)$, genetic diversity, market opportunities, and advanced genomic tools [8-11]. A critical aspect of improving saccharification of Populus trees has been the risk for growth penalties when modifying wood properties for reduced recalcitrance. Even though improved saccharification of transgenic trees has been obtained without growth penalties [12-15], most often increased saccharification is associated with impaired growth [16-22]. It is, therefore, important to identify novel ways to reduce feedstock recalcitrance to saccharification by enzymatic hydrolysis. Furthermore, most of the above-mentioned examples of improved saccharification without growth penalties require re-examination under field conditions.

A large-scale gene-mining program was launched in hybrid aspen (Populus tremula $\times$ tremuloides) to identify genes improving wood properties and/or chemistry by transgenic means [23]. We screened a selected set of transgenic lines derived from this program to identify novel approaches to increase saccharification yields without concomitant growth penalties [22]. One of the most promising lines concerned modification of a Populus VAP27-17 gene (Line BI-36, [22]). VAPs [vesicle-associated membrane protein (VAMP)-associated proteins] are well-conserved, eukaryotic proteins, which work as tethers at endoplasmic reticulum-plasma membrane contact sites (EPCSs) or between ER and endosomes [24, 25]. In the present study, the function of the Populus tremula $\times$ tremuloides VAP27-17 (PttVAP27-17) was characterized in transgenic hybrid aspen lines both in the greenhouse and in a 5-year field trial. Analyses of transgenic trees both in the greenhouse and for 5 years in the field showed that constitutive overexpression of PttVAP27-17 has potential to increase the whole-tree saccharification yields due to increases in biomass production, making this approach interesting from a biotechnological point of view.

\section{Results}

\section{A VAP27 gene family member is a candidate gene} for improved saccharification

In the course of our efforts to identify novel genes that improve bioprocessing properties of woody plants, we identified earlier a Populus tremula $\times$ tremuloides gene that encodes a member of the VAP27 gene family [22]. We first characterized the VAP27 gene families in Populus trichocarpa and Arabidopsis thaliana (Arabidopsis from here on) genomes. Arabidopsis genome contains 10 $V A P 27$ genes, which have been reported to cluster into three subfamilies: I, II, and III [25]. These genes were found to belong to two PLAZA (v4.0, [26]) gene families: HOM04D000560 and HOM04D001450. Seventeen P. trichocarpa genes (PtrVAP27) were identified in these two PLAZA gene families. Phylogenetic analysis of the corresponding Arabidopsis and P. trichocarpa proteins revealed a bigger group of proteins that included both the Arabidopsis subfamily I and III proteins and 11 homologous $P$. trichocarpa proteins (PttVAP27-1-PttVAP27-11), and a quite distantly related, smaller group containing the Arabidopsis subfamily II proteins together with six P. trichocarpa proteins (PttVAP27-12-PttVAP27-17) (Fig. 1a). Since transgenic trees were created in this study to specifically modify expression of the Potri.019G116400 homologue in $P$. tremula $\times$ tremuloides, which belongs to the smaller group, we focus here on the properties of the proteins in this group.

Populus VAP27-12, -13, -14, -15, -16 and -17 proteins (Fig. 1a) contain each an MSP (major sperm protein) domain (predicted by SMART-EMBL) located centrally rather than towards the $\mathrm{N}$-terminus as observed for the other VAP27 proteins, and a coiled-coil domain (CCD, after amino-acid residue 200, Coiled Coil prediction of Prabi-Gerland site; [27]), which is common in most VAP and SNARE proteins. They have no transmembrane domain (TMD) in the $C$-terminal region (predicted by Phobius; [28]).

Expression data for the Populus VAP27-12, -13, -14, $-15,-16$ and -17 genes were retrieved from the AspWood gene expression database [10] which contains high-resolution RNA sequencing data for different stages of wood development in the aspen (P. tremula) stem (Fig. 1b). PttVAP27-17 displayed low expression in the phloem/ 


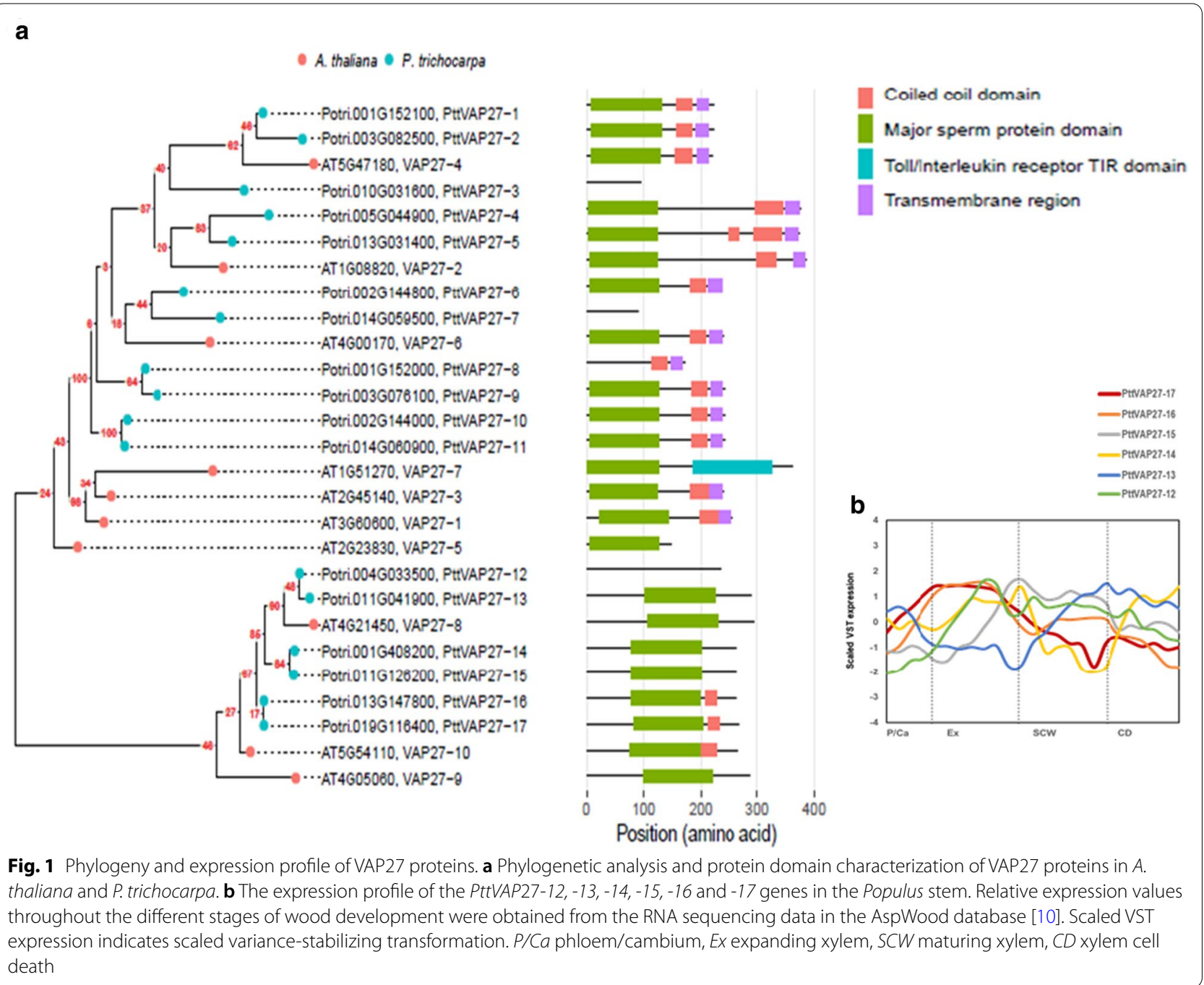

cambium region of the stem, followed by a peak in the area of xylem expansion, and decreased expression during xylem maturation and cell death (Fig. 1b). This expression pattern is consistent with a function in early xylem development.

\section{Overexpression of PttVAP27-17 has potential to increase growth in greenhouse-grown trees}

Transgenic PttVAP27-17 overexpression lines, carrying a construct with the PttVAP27-17 gene under the control of the constitutive CaMV $35 S$ promoter, were analyzed in detail for their performance in greenhouse conditions. Three transgenic $P$. tremula $\times$ tremuloides lines (lines 1 , 2 , and 3) were grown for two months in the greenhouse. The expression of PttVAP27-17 was increased by 75-, 92- and 29-fold in the transgenic lines 1,2 , and 3, respectively, compared to the wild type (WT) (Fig. 2a). Quantitative PCR results confirmed these results (Fig. 2b).
Overexpression of PttVAP27-17 did not result in statistically significant differences in the expression of the other closely related $P$. tremula $\times$ tremuloides VAP27 genes (Fig. 2a).

After two months of growth in the greenhouse, all three transgenic lines showed trends towards increased growth even though statistically significant differences were found only for line 3 (Fig. 2c-f).

Wood chemical analyses using mature wood from the basal part of the stems were performed with two different methods, Py-GC/MS (pyrolysis-gas chromatography/ mass spectrometry) and by high-performance anionexchange chromatography after hydrolysis of carbohydrates with sulfuric acid. Py-GC/MS, which defines the abundance of wood pyrolytic products as GC peak areas in relation to the total peak area, did not reveal any significant differences even though a tendency towards increased total carbohydrate content and decreased 

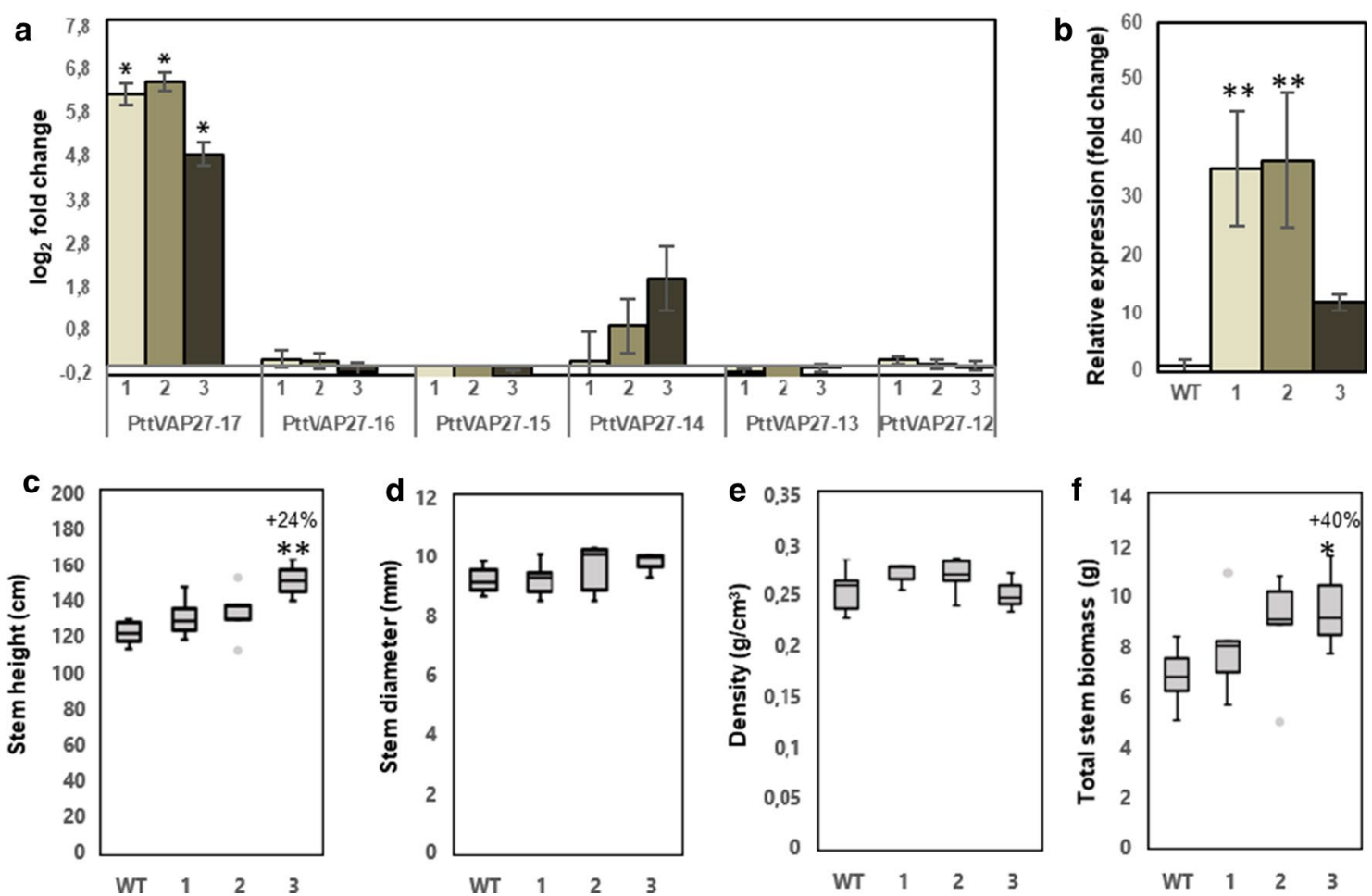

Fig. 2 Overexpression of PttVAP27-17 in greenhouse-grown hybrid aspen trees. a The expression of PttVAP27-12,-13,-14,-15,-16 and -17 genes in stem tissues of three transgenic $P$. tremula $\times$ tremuloides lines (1-3) carrying the 355::PttVAP27-17 construct. The expression data were derived from the transcriptomic analysis of secondary xylem tissues collected from the basal part of 2-months-old greenhouse-grown trees. The log2 fold-change indicates log ratio of PttVAP27-17 expression in each transgenic line compared to WT. The figure also shows relative expression of PttVAP27-17 by qPCR (b), stem height (c), stem diameter $(\mathbf{d})$, wood density $(\mathbf{e})$, and total stem biomass (f) in the three transgenic P. tremula $\times$ tremuloides lines carrying the 35S::PttVAP27-17 construct and the WT grown for two months in the greenhouse. Stem volume was estimated using the formula: volume $=\pi \times$ radius $^{2} \times$ height/3. $n=5$ for transgenic line 1 and $2, n=3$ for transgenic line 3 and $n=7$ for the WT where " $n$ " indicates number of biological replicates. Vertical bars (in $\mathbf{a}, \mathbf{b}$ ) indicate $\pm S D$. The box plots show the median (horizontal line) with the outer limits at the 25th and 75th percentiles, the 1.5 inter-quartile ranges (whiskers) and the outliers (gray spots). Asterisks indicate statistically significant differences compared to WT: $p \leq 5 \%\left({ }^{*}\right), p \leq 0.1 \%\left({ }^{* *}\right)$, using Student's $t$-test $(\mathbf{b}, \mathbf{c}, \mathbf{f})$ and differential expression analysis DESeq2 (a). Percentages indicate increase $(+)$ or decrease $(-)$ of corresponding data values for lines overexpressing PttVAP27-17 compared to WT

lignin content was observed in the transgenic lines (Fig. 3a, b and Additional file 1: Table S2). Compositional analysis indicated that the transgenic lines displayed a tendency towards increased glucan content, which was statistically significant for line 1 (Fig. 3i). Altogether, these analyses demonstrate that the increased biomass production of the transgenic lines coincided with minor increases in the carbohydrate constituents and minor decreases of the lignin content of the cell walls.

\section{Overexpression of PttVAP27-17 has an impact}

\section{on saccharification efficiency in greenhouse-grown trees}

An important parameter for biotechnology purposes is susceptibility of cell wall carbohydrates to enzymatic saccharification. We, therefore, investigated whether overexpression of PttVAP27-17 influenced the analyticalscale enzymatic saccharification with or without a prior hydrothermal pretreatment step with sulfuric acid. The principal target of this type of pretreatment is the hemicellulose. The pretreatment resulted in a liquid phase, referred to as pretreatment liquid or hemicellulosic hydrolysate. As expected, xylose was the predominant sugar in the liquid phase (Additional file 1: Table S11a). Subsequent enzymatic saccharification of the solid phase after pretreatment resulted in an enzymatic hydrolysate in which glucose was the predominant sugar (Additional file 1: Table S11a). The yields of glucose after enzymatic saccharification of pretreated solid phase were not altered in the transgenic lines compared to the WT (Fig. 4d and Additional file 1: Table S11a). However, the glucose yields after enzymatic saccharification of unpretreated wood were increased by $20-44 \%$ for the transgenic lines compared to the WT even though it was statistically significant only in line 1 (Fig. $4 \mathrm{c}$ and Additional file 1: Table S11a). 

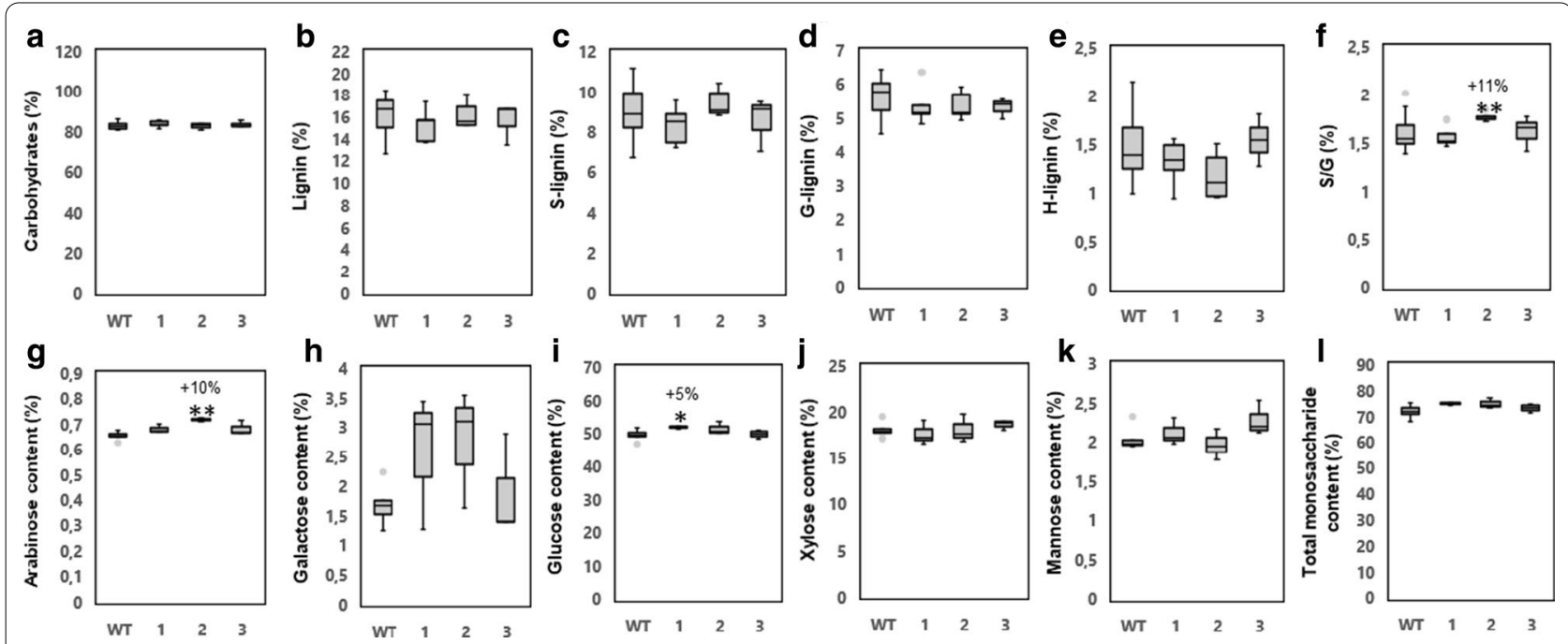

Fig. 3 Overexpression of PttVAP27-17 did not cause major changes in wood chemistry of greenhouse-grown trees. a-f Pyrolysis-gas

chromatography/mass spectrometry analysis of cell wall components in wild type (WT) and three PttVAP27-17 lines (1-3). The values are relative, and depict the combined area of GC peaks assigned to carbohydrates (C), lignin (L), syringyl lignin (S-lignin), guaiacyl lignin (G-lignin) and p-hydroxyphenyl lignin (H-lignin) as a percentage of total GC peak area. S/G, ratio between syringyl and guaiacyl-type lignin. g-ITotal carbohydrate content in WT and PttVAP27-17 lines measured by high-performance anion-exchange chromatography. The fractions of arabinose, galactose, glucose, xylose, mannose, and total monosaccharides (arabinose + galactose + glucose + xylose + mannose) after acid hydrolysis are indicated as percentages ( $\mathrm{g}$ of monosaccharide sugar in anhydrous form per $100 \mathrm{~g}$ of dry weight of wood). Wood chemical analyses were performed using mature wood from the basal part of the stem of two-months-old trees grown in the greenhouse. For both type of analyses, $n=5$ for transgenic line 1 and $2, n=3$ for transgenic line 3 where " $n$ " indicates number of biological replicates. For the WT, 33 biological replicates were used without pooling for pyrolysis-gas chromatography/mass spectrometry analysis and with pooling to five replicates for total carbohydrate content analysis. The box plots show the median (horizontal line) with the outer limits at the 25th and 75th percentiles, the 1.5 inter-quartile ranges (whiskers) and the outliers (gray spots). Asterisks indicate significant differences from the WT at $p \leq 5 \%\left({ }^{*}\right)$ and $p \leq 0.1 \%\left(^{* *}\right)$ according to Student's $t$-test. Percentages indicate increase $(+)$ or decrease $(-)$ of values of lines overexpressing PttVAP27-17 in comparison to WT
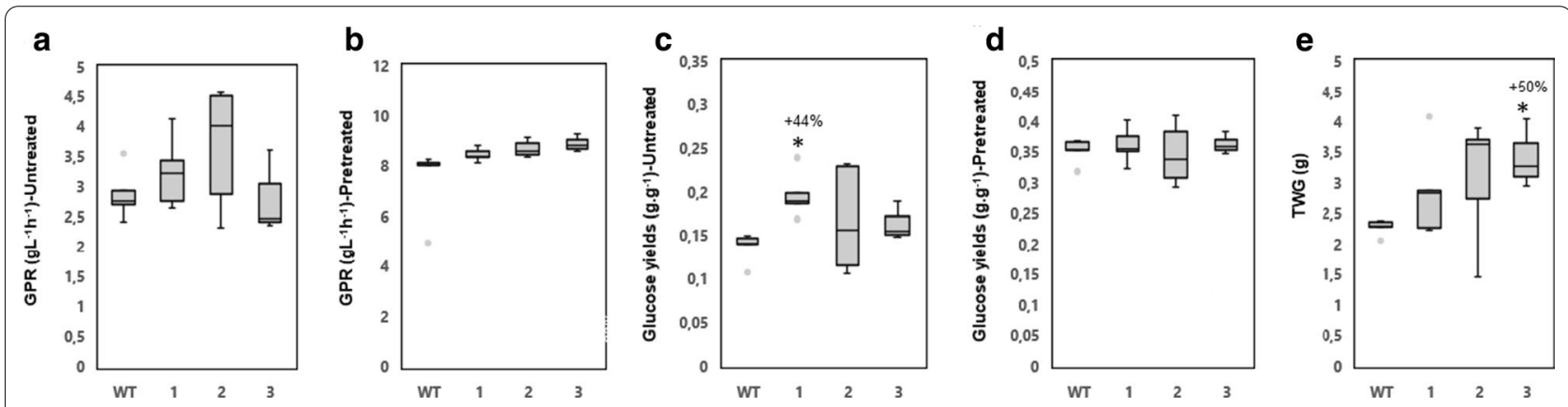

Fig. 4 The impact of the overexpression of PttVAP27-17 on the enzymatic saccharification of greenhouse-grown trees. $\mathbf{a}$, $\mathbf{b}$ Glucose production rate (GPR) after $2 \mathrm{~h}$ of enzymatic saccharification $\left(\mathrm{gL}^{-1} \mathrm{~h}^{-1}\right)$ for samples without (untreated) and with acid pretreatment (pretreated) in wild type (WT) and three transgenic lines (1-3). c, $\mathbf{d}$ Glucose yields after $72 \mathrm{~h}$ of enzymatic saccharification [g glucose per $\mathrm{g}$ of wood (dry weight) in samples without (untreated) and after acid pretreatment (pretreated)]. e Total wood glucose yield (TWG) after pretreatment and $72 \mathrm{~h}$ of enzymatic

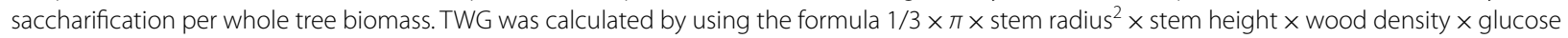
yield after pretreatment and $72 \mathrm{~h}$ of enzymatic saccharification. $n=5$ for transgenic line 1 and $2, n=3$ for transgenic line 3 and $n=33$ for the WT where " $n$ " indicates number of biological replicates. Samples from the $33 \mathrm{WT}$ trees were pooled to five replicate samples in all these experiments. The box plots show the median (horizontal line) with the outer limits at the 25th and 75th percentiles, the 1.5 inter-quartile ranges (whiskers) and the outliers (gray spots). Asterisks indicate significant differences from the WT at $p \leq 5 \%\left({ }^{*}\right)$ according to Student's $t$-test. Percentages indicate increase $(+)$ or decrease $(-)$ of values for lines overexpressing PttVAP27-17 compared to the WT 
Another important parameter is the rate of glucose production during saccharification. We measured the glucose production rate (GPR) after $2 \mathrm{~h}$ of enzymatic hydrolysis with and without acid pretreatment. For all transgenic lines, the GPR increased by $13-16 \%$ compared to the WT after enzymatic hydrolysis with and without pretreatment, even though it was not statistically significant (Fig. 4a, b). Overall, the glucose yields after enzymatic hydrolysis without pretreatment suggest that the genetic modification caused by overexpression of PttVAP27-17 affected cell wall components in a way that made the cellulose more easily accessible to enzymatic hydrolysis.

Finally, the total-wood glucose (TWG) yield was estimated. TWG estimates glucose yield after pretreatment and $72 \mathrm{~h}$ enzymatic hydrolysis per total stem woody biomass, and hence integrates saccharification properties (per gram dry weight) with biomass production of trees [22]. All transgenic lines had higher TWG compared to the WT, but it was statistically significant only for line 3 (Fig. 4e). The saccharification results are in agreement with our previous study, where the VAP27-17 overproduction line 3 (called "BI 36" in [22]) was identified as one of the lines with highest TWG [22]. Increased TWG in the transgenic line 3 demonstrates that saccharification yields can be significantly improved in trees having increased biomass production even though sugar yields per dry weight are not higher.

A multi-omics approach provides a toolbox for the analysis of PttVAP27-17 function

Transgenic modifications aiming towards improved saccharification properties of the feedstock should not negatively influence important metabolic processes. Using the methodology described by Obudulu et al. [29], a multi-omics approach was used to characterize the overall effect of overexpression of PttVAP27-17 on plant metabolic pathways. The analytical platforms included transcriptomics, metabolomics (UHPLC-MS, ultra-high-performance liquid chromatography-mass spectrometry), proteomics, GC-MS for monosaccharide sugars, and Py-GC/MS analyses of woody tissues from greenhouse-grown trees. An OnPLS analysis [30-33] was performed on data from the WT and combined data from the three lines overexpressing PttVAP27-17. OnPLS separates data from each analytical platform into three different parts depending on whether the data variation is globally joint (shared between all analytical platforms), locally joint (shared between some, but not all analytical platforms), or unique (specific for one analytical platform). The analysis was introgressed into an OnPLS model, which revealed that the majority of the modeled variation was globally joint, which when combined with the locally joint variation included $67 \%$ of transcriptome variation, $65 \%$ of proteome variation, $79 \%$ of UHPLC-MS variation, $86 \%$ of GC-MS variation, and $61 \%$ of $\mathrm{Py}-\mathrm{GC} /$ MS variation. An overview of OnPLS integration of the five platforms using correlation plot revealed that the significantly different variables $(\mid p($ CORR $) \mid \geq 0.5)$ between the transgenic lines and the WT were best described on the basis of the first component of the OnPLS (Additional file 1: Fig. S1) [34].

The OnPLS analysis revealed a large number of genes that were differentially expressed but only a small number of proteins and metabolites that were changed in abundance in the lines overexpressing PttVAP27-17 compared to the WT (Table 1). Several genes annotated with microtubule-related functions were more expressed in the transgenic lines compared to the WT (Additional file 1: Tables S5-S7). Also gene ontology (GO) enrichment analysis (using the tool REVIGO from Popgenie home page [35]) of the significantly differentially expressed genes and proteins $(|p(\mathrm{CORR})| \geq 0.5)$ revealed enrichment of genes and proteins involved in microtubule-based processes or movement of cellular components in the transgenic lines (Additional file 1: Tables S9 and S10). Other cellular components that dominated in the GO analyses were associated with non-membrane bound organelles and the (clathrin) vesicle part/coat. Also, a few other biological processes, such as (purine)

Table 1 Number of significantly different variables $(|p(C O R R)| \geq 0.5)$ between the PttVAP27-17 overexpressed lines and the WT of the greenhouse-grown trees on the basis of the first globally joint component of the OnPLS analysis

\begin{tabular}{lccc}
\hline Analytical platform & $\begin{array}{l}\text { Total number } \\
\text { of variables }\end{array}$ & $\begin{array}{l}\text { Number of variables significantly down- } \\
\text { regulated in transgenic lines compared to WT }\end{array}$ & $\begin{array}{l}\text { Number of variables significantly } \\
\text { up-regulated in transgenic lines } \\
\text { compared to WT }\end{array}$ \\
\hline Transcriptomics & 26,444 & 2105 & 2616 \\
Proteomics & 928 & 2 & 85 \\
Metabolites (UHPLC-MS) & 992 & 37 & 101 \\
Metabolites (Py-GC/MS) & 109 & 2 & 5 \\
Metabolites (GC-MS) & 213 & 2 & 30
\end{tabular}


ribonucleoside and ribonucleotide metabolism/binding, glycolysis, monosaccharide metabolism, and carbohydrate catabolism appeared in the GO analysis of differentially expressed genes and proteins. Taken together, the multi-omic analyses revealed both changes that one would expect as a result of a VAP27 protein overexpression as well as alterations in metabolic pathways that are not previously connected to VAP27 function. It is possible that some of these changes in metabolic pathways are secondary due to changes in the growth of the PttVAP27-17 overexpressing trees, but the possibility that they are causally related to these changes cannot be excluded. In any case, the rather small number of metabolic pathway proteins that were significantly altered in the transgenic lines (Table 1 and Additional file 1: Table S7) suggests that PttVAP27-17 overexpression had rather limited effects on major metabolic processes.

\section{Overexpression of PttVAP27-17 can increase total biomass production also in field-grown transgenic trees}

Greenhouse experiments were validated in field trials in southern Sweden. The transgenic trees were grown together with WT trees for five growing seasons (August 2011-August 2016). An additional transgenic line, line 4, was added to this trial. Growth was measured twice during each growing season, and trees were analyzed with regard to wood properties at the end of the growth trial.

Similar to the greenhouse-grown trees, overexpression of PttVAP27-17 showed potential to increase growth of the trees in the field. Compared to the WT, lines 2 and 4 had increased stem height after the 5 -year growth period
(Fig. 5a). The stem diameter was not altered significantly (Fig. 5b). All lines tended to have increased wood density, which together with the increase in stem height resulted in increased total stem biomass even though it was statistically significant only for line 2 (Fig. 5c).

Total carbohydrate and $\mathrm{Py}-\mathrm{GC} / \mathrm{MS}$ analyses did not reveal any consistent changes in wood chemistry among the PttVAP27-17 overexpression lines compared to the WT (Fig. 6). A tendency towards lower lignin content was present in all transgenic lines compared to the WT (Fig. 6b). Unlike the greenhouse-grown trees, the saccharification efficiency of the field-grown trees did not show any improvement, and some of the lines had even lower sugar yields compared to WT (Fig. 7a-d and Additional file 1: Table S11b). However, the total-wood glucose yield (TWG) tended to increase (by 9-24\%) in three out of the four PttVAP27-17 lines (Fig. 7e).

\section{Discussion}

Our study shows that overexpression of PttVAP27-17 has potential to improve growth and biomass production not only in greenhouse conditions but also in the field, even though the results varied between the transgenic lines in the two different growth conditions (Figs. 2 and 5). Several studies have demonstrated increased growth of genetically modified trees or specific tree genotypes $[13,15,36]$. However, our study is one of the few where transgenic trees have also been tested in field conditions and where data are shown for several independent transgenic lines. In other studies, trees that displayed increased growth in the greenhouse performed either the same or worse in the field $[19,37]$. Our results stand
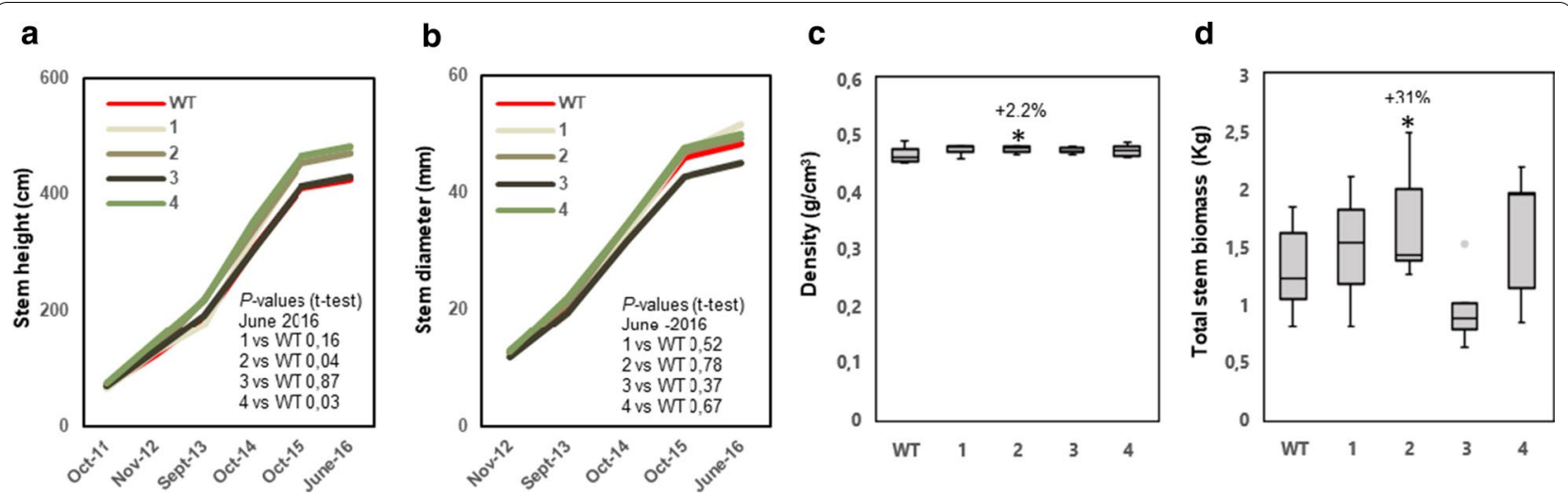

Fig. 5 Overexpression of PttVAP27-17 can increase stem biomass in field-grown trees. Stem height (a), stem diameter (b), wood density (c) at the base of the stem and total stem biomass (d) in field-grown trees of the wild type and four transgenic lines (1-4) during four seasons of growth (a, b) or at the end of the 5-year field trial (c, d). $n=3$ for transgenic line 1, $n=5$ for transgenic line 2, 3, 4 and 19 for the WT where " $n$ " indicates number of biological replicates. The box plots show the median (horizontal line) with the outer limits at the 25th and 75th percentiles, the 1.5 inter-quartile ranges (whiskers) and the outliers (gray spots). Asterisks indicate significant differences compared to the WT at $p \leq 5 \%(*)$, according to Student's $t$-test. The volumes of the stems were estimated using the formula: volume $=\pi \times$ radius ${ }^{2} \times$ height/3. Total stem biomass was defined on the basis of the stem volume and density. Percentages indicate increase (+) or decrease (-) for lines overexpressing PttVAP27-17 in comparison to the WT 

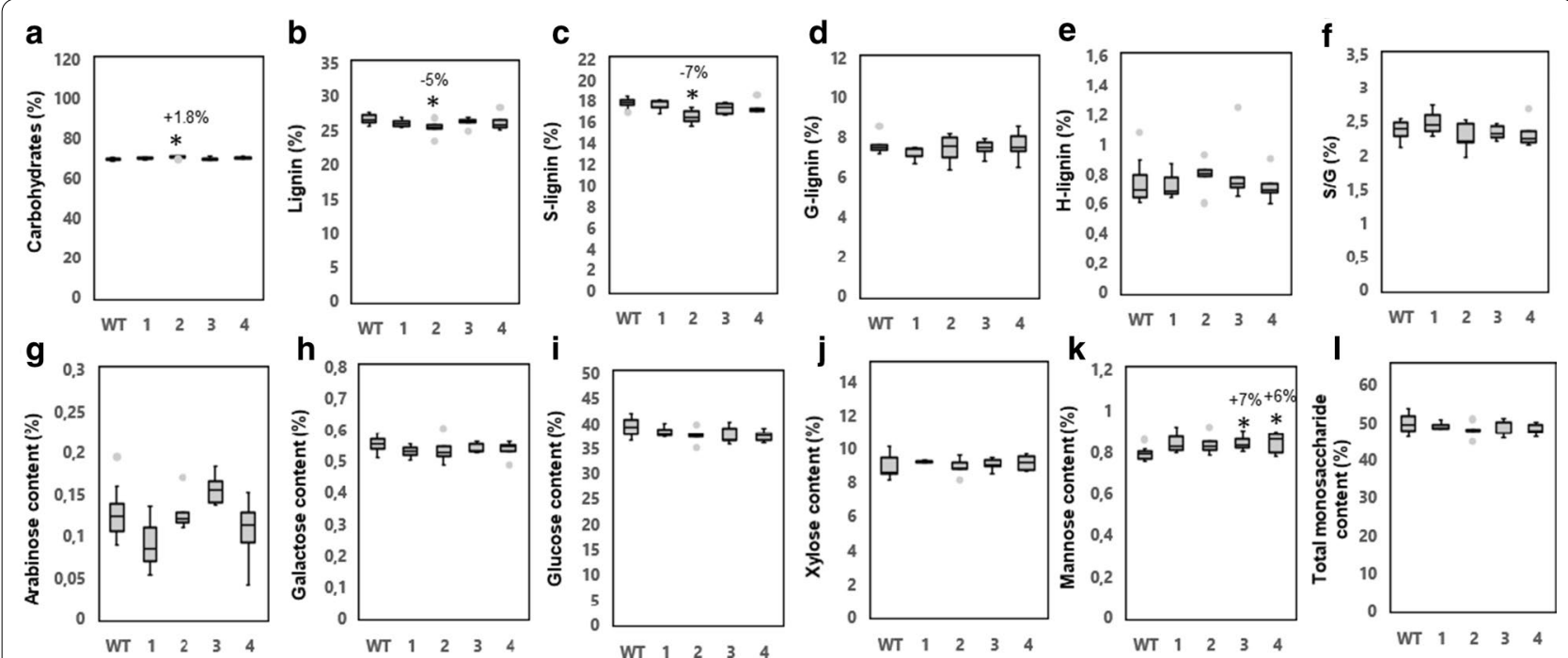

Fig. 6 Overexpression of PttVAP27-17 affected only slightly the wood chemistry of field-grown trees. a-f Py-GC/MS analysis of cell wall components in WT and four PttVAP27-17 lines (1-4). The values are relative, and depict the combined area of GC peaks assigned to carbohydrates (C), lignin (L), syringyl lignin (S-lignin), guaiacyl lignin (G-lignin) and p-hydroxyphenyl lignin (H-lignin) as a percentage of total GC peak area. S/G, ratio between syringyl and guaiacyl-type lignin. g-ITotal carbohydrate content for WT and PttVAP27-17 lines 1-4 determined by high-performance anion-exchange chromatography. The fractions of arabinose, galactose, glucose, xylose, mannose, and total monosaccharides (arabinose + galactose + glucose + xylose + mannose) released after acid hydrolysis are indicated as percentages ( $\mathrm{g}$ of monosaccharide sugar in anhydrous form per $100 \mathrm{~g}$ of dry weight of wood). For all analyses, mature wood was collected from the base of the stem of 5-year-old trees grown in the field. $n=3$ for transgenic line $1, n=5$ for transgenic line 2, 3, 4 and $n=8$ for the WT where " $n$ " indicates number of biological replicates. The box plots show the median (horizontal line) with the outer limits at the 25 th and 75 th percentiles, the 1.5 inter-quartile ranges (whiskers) and the outliers (gray spots). Asterisks indicate significant differences from the WT at $p \leq 5 \%\left(^{*}\right)$ according to Student's $t$-test. Percentages indicate increase $(+)$ or decrease $(-)$ in values for lines overexpressing PttVAP27-17 compared to the WT
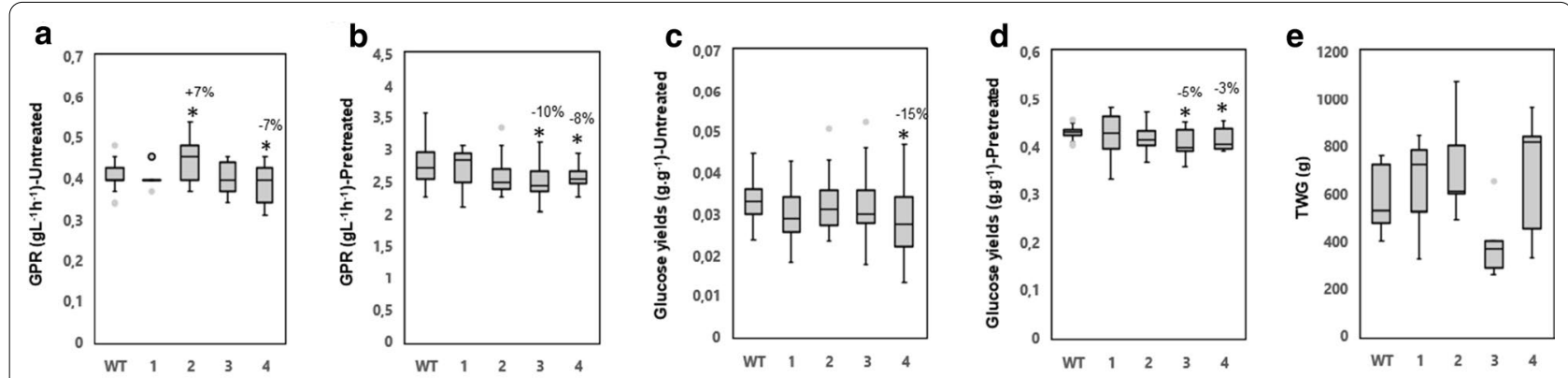

Fig. 7 The impact of the overexpression of PttVAP27-17 on the enzymatic saccharification in woody tissues of field-grown trees. $\mathbf{a}$, $\mathbf{b}$ Glucose production rate (GPR) after $2 \mathrm{~h}$ of enzymatic saccharification $\left(\mathrm{gL}^{-1} \mathrm{~h}^{-1}\right)$, for samples without (untreated) and with acid pretreatment (pretreated) in wild type and four transgenic lines (1-4). c, $\mathbf{d}$ Glucose yields after $72 \mathrm{~h}$ of enzymatic saccharification [g glucose per $\mathrm{g}$ of wood (dry weight) without (untreated) and with acid pretreatment (pretreated)]. e Total wood glucose yield (TWG) after pretreatment and $72 \mathrm{~h}$ of enzymatic saccharification per whole tree stem biomass. TWG was calculated by using the formula $1 / 3 \times \pi \times$ radius $^{2} \times$ height $\times$ wood density $\times$ glucose yield after pretreatment and $72 \mathrm{~h}$ of enzymatic saccharification. $n=3$ for transgenic line 1, $n=5$ for transgenic line $2,3,4$ and $n=8$ for the WT; where " $n$ " indicates number of biological replicates. Mature wood was collected from the base of the stem of 5 -year-old trees grown in the field. The box plots show the median (horizontal line) with the outer limits at the 25 th and 75 th percentiles, the 1.5 inter-quartile ranges (whiskers) and the outliers (gray spots). Asterisks indicate significant differences from the WT at $p \leq 5 \%\left(^{*}\right)$, according to Student's $t$-test. Percentages indicate increase $(+)$ or decrease ( - ) in values for lines overexpressing PttVAP27-17 compared to the WT

out considering that the conditions in the field were quite uneven, as no extra irrigation was provided to the trees. The genotype used in these studies (T89) is also poorly adapted to the ambient conditions in southern Sweden as it originates from the Czech Republic. One of the transgenic PttVAP27-17 overexpression lines (line 3) grew 
quite differently in the greenhouse and in the field. While line 3 performed best among the three lines in the greenhouse, it had the lowest biomass production among the four tested lines in the field conditions. The reason for this is not known, but it emphasizes the importance of testing transgenic lines also in field conditions to find the best-suited material for downstream processes.

Analyses of the transgenic PttVAP27-17 trees revealed slightly increased saccharification rates and glucose yields in the greenhouse conditions (Fig. 4a-d). These trends were only observed without pretreatment, which could be related to tendencies towards lower lignin accumulation of the transgenic lines and hence increased accessibility of cellulose to enzymatic saccharification (Figs. 3b, 6b). Also, metabolic profiles suggested a decrease in lignin-specific oligomers, such as 5-O-4-coumaroyl shikimate, 5-O-caffeoyl shikimic acid and 6-hydroxy2-cyclohexen-on-oyl sinapic acid ( $\mathrm{HCH}$-sinapic acid) in the transgenic trees (Additional file 1: Table S3). However, the saccharification efficiency was not improved in the transgenic trees collected from the field (Fig. 7a-d). But due to the slightly higher biomass production of the trees, the whole tree saccharification efficiency, as measured by the total wood glucose yield, tended to increase in three field-grown lines out of four when compared to the wild type (Fig. 7e).

Saccharification assays have rarely been performed in conditions resembling natural, ambient conditions. Downregulation of cinnamoyl-CoA reductase (CCR) gene in field-grown Populus trees resulted in improved saccharification yields (per gram dry weight) at two field sites, but for all but one transgenic line that effect was outweighed on a whole-tree basis by reduced biomass production [19]. In another study, downregulation of the 4-coumarate:coenzyme A ligase (4CL) gene using a xylem-specific promoter resulted in reduction in biomass growth, reduction in lignin content, and a negative impact on the saccharification efficiency in field-grown hybrid poplar lines [37]. However, downregulation of the same gene in P. trichocarpa using the $35 S$ promoter resulted in increased saccharification rates, but no description on tree growth was presented [38, 39]. The current study is, therefore, unique in the sense that it provides evidence from field-grown Populus trees on the potential of PttVAP27-17 overexpression to increase saccharification yields without concomitant growth penalties.

Even though this study did not aim to investigate the exact function of PttVAP27-17, our multi-omic results support its involvement in microtubule organization. In line with this, an ER-associated Arabidopsis VAP27-1 protein was shown to bind to microtubules in vitro, suggesting that it is involved in ER anchoring to microtubules [40]. Our proteomic analyses also revealed alterations in the abundance of proteins related to vesicle trafficking and clathrin-coated vesicles, supporting a function of PttVAP27-17 in endocytosis. Arabidopsis VAP27-1 and VAP27-3 were recently shown to interact with clathrin and phosphatidyl inositol-phosphate (PIP) lipids [41]. It was proposed that these ER-localized VAP proteins are required for tethering ER with the PIPenriched domains of the plasma membrane to maintain endocytic trafficking. It is possible that PttVAP27-17 is involved in a similar kind of process even though PttVAP27-17 seems to have a predominant localization in the plasma membrane, in analogy with its closest Arabidopsis homologs VAP27-8 and -10 [25]. Therefore, the possible role of PttVAP27-17 in microtubule function and endocytosis, and how these processes influence plant growth remain to be investigated further. Our datasets on PttVAP27-17-related transcriptomics, proteomics, and metabolomics provide a toolbox for these purposes.

\section{Conclusions}

The study reports on an alternative strategy to increase saccharification yields by increasing the biomass production of trees while maintaining adequate saccharification rates. Overexpression of PttVAP27-17 in transgenic Populus trees was identified as a promising tool for such a strategy on the basis of experiments performed both in the greenhouse and on field conditions.

\section{Methods}

\section{Generation of greenhouse-grown transgenic plants and tissue sampling}

Transgenic lines were produced by SweTree Technologies $A B$, Sweden, as a part of their large-scale gene-mining program in hybrid aspen (Populus tremula $\times$ tremuloides). The PttVAP27-17 overexpression construct was created by amplifying a fragment from Populus tremula $\times$ tremuloides cDNA corresponding to gene model Potri.019G116400 with the forward primer GAAAGTTTAGTCTTTGCAAAATGCC and the reverse primer ACAAGTGCTTACAAGGAAAAC AGG, followed by recombination into pDONOR201 and further into $\mathrm{pK} 2 \mathrm{GW} 7$, under the control of the $35 \mathrm{~S}$ promoter. The resulting vector was transformed into hybrid aspen (P. tremula $\times$ tremuloides) clone T89 according to Nilsson et al. [42]. Several transgenic lines were grown in the greenhouse, and four lines $(1,2,3$ and 4) were selected for this study on the basis of the greatest separation in growth from a large population of WT trees in a PCA analysis.

Three transgenic lines (1, 2, 3; each with 3-5 trees) and the WT (T89 with 33 biological replicates) were grown in greenhouse under controlled conditions as described 
in Obudulu et al. [29]. Samples were collected from the basal part of the tree; the $10-17 \mathrm{~cm}$ portion from the base of the stem was used for metabolomics, proteomics, and transcriptomics studies, the $33-36 \mathrm{~cm}$ portion for anatomical studies [fixed in a solution containing formaldehyde (5\%), acetic acid (5\%), and ethanol (50\%)], and the 36-46 cm portion for wood chemical analysis, saccharification studies, and density measurements. Density was measured by the water-replacement method.

\section{Phylogenetic analysis}

The evolutionary history was inferred using the WAG substitution model [43]) in the $\mathrm{R}$ package phangorn (v2.2.0; [44]). Bootstrap support values in the phylogram were based on 1000 bootstrap runs. Visualization was performed in R using the ggtree extension (v1.12.7; [45]) for ggplot2 (v3.0.0; [46]). Protein domain detection was done using InterProScan (v5.27-66.0; [47]) and consequently visualized using ggplot 2 .

\section{Transcriptomics, proteomics, and metabolomics}

The frozen part of the stem $(10-17 \mathrm{~cm}$ portion from the base of the stem) was peeled from the greenhouse-grown trees, and the surface of the secondary xylem consisting of living vessels and fibers (into the depth of approximately $1 \mathrm{~mm}$ from the surface) was scraped. The xylem scrapings were ground to fine powder in liquid nitrogen and stored at $-80{ }^{\circ} \mathrm{C}$ for transcriptome, proteome and metabolome analysis. The analyses included 3-5 biological replicates for each of the transgenic lines, and seven WT trees that were selected with a multivariate analysis to adequately represent the whole population of 33 wildtype trees that were grown at the same time with the transgenic lines in a random fashion.

\section{Transcriptome analysis}

Total RNA was extracted and sequenced at the Beijing Genome Institute (China) following the protocol described by Obudulu et al. [29]. The gene expression data were aligned using STAR [48] and were normalized with variance-stabilizing transformation (VST) using the R package DESeq2 [49].

\section{Proteome analysis}

Following the procedure described in Obudulu et al. [29], proteome analysis was performed from $20 \mathrm{mg}$ of xylem sample for the selected WT and transgenic trees. Protein identification and peptide quantification was done according to Srivastava et al. [50]. Protein abundances were calculated by taking the median from the abundances of the unique peptides that matched with a protein and that showed a significance level of 0.05 corresponding to a $|p(\mathrm{CORR})| \geq 0.5$ in the OnPLS analysis.

\section{Metabolite profiling using GC-MS and UHPLC-MS}

Metabolite analyses using GC-MS and UHPLC-MS were performed following the procedures described by Jonsson et al. [51] and Obudulu et al. [29], respectively.

\section{qPCR analysis}

Quantitative PCR analysis was performed in the same samples that were used for the transcriptome analysis by RNAseq, according to Obudulu [29], using primers ATCCAGAATGCCCTAGTCCTGCAC and AAG TCCTTCGCCAACAACTCTGG for PttVAP27-17 and primers GGCTAATTTTGCCGATGAGA and ACG TCCATCCCTTCAACAAC for the reference cyclophilin gene (Potri.004G168800).

\section{Chemical and structural analysis of wood}

Freeze-dried wood of transgenic and WT trees from the $36-46 \mathrm{~cm}$ stem portion for the greenhouse-grown trees and $5 \mathrm{~cm}$ bottom stem portion for the field-grown trees was cut into small chips and milled using an A11 Basic Analytical Mill (IKA, Staufen, Germany), followed by grinding in an Ultra Centrifugal mill ZM 200 (Retsch $\mathrm{GmbH}$, Haan, Germany) equipped with a $0.5 \mathrm{~mm}$ ring sieve. The wood powder was processed further by passing it through an analytical sieve shaker AS 200 (Retsch $\mathrm{GmbH}$ ) to collect wood powder of particle size in the range $0.1-0.5 \mathrm{~mm}$. For $\mathrm{Py}-\mathrm{GC} / \mathrm{MS}$ and sugar analysis using GC-MS after acidic methanolysis, milled wood powder was further ground into a fine powder using $12 \mathrm{~mm}$ grinding balls at $30 \mathrm{~Hz}$ for $2 \mathrm{~min}$ in an MM400 bead mill (Retsch $\mathrm{GmbH}$ ).

\section{Pyrolysis-gas chromatography/mass spectrometry (Py-GC) MS)}

Finely milled wood powder $(50 \mu \mathrm{g})$ from each individual transgenic (3-5 per line) and WT (33 biological replicates from the greenhouse and eight biological replicates from the field) tree was loaded into an oven pyrolyser set at $450{ }^{\circ} \mathrm{C}$ (with an interface and injector at $340{ }^{\circ} \mathrm{C}$ and $320^{\circ} \mathrm{C}$, respectively) and equipped with an autosampler (PY-2020iD and AS-1020E, FrontierLabs, Japan) connected to a GC/MS (7890A/5975C; Agilent Technologies, Kista, Sweden). The pyrolysate was separated on a DB-5MS capillary column (J\&W, Agilent Techologies $A B$ ) and analyzed following the method used by Gerber et al. [52]. 
Analysis of monosugars by GC-MS after acidic methanolysis Finely milled wood powder from all transgenic (3-5 per line) and WT (33) trees was used for monosugar analysis of the greenhouse-grown trees. Extractives were removed with $80 \%$ ethanol in HEPES buffer (4 mM, pH 7.5) for $30 \mathrm{~min}$ at $95{ }^{\circ} \mathrm{C}$, followed by methanol:chloroform (1:1) extraction and two washes with acetone. To remove starch, the extractive-free wood powder was treated overnight at $37{ }^{\circ} \mathrm{C}$ with $\alpha$-amylase from pig pancreas (Roche 10102814001; 100 units per $100 \mathrm{mg}$ of wood) in potassium phosphate buffer $(0.1 \mathrm{M}, \mathrm{pH}$ 7.0). For the quantification of monosugars, $0.5 \mathrm{mg}$ of amylase-treated extractive-free wood was methanolyzed using $2 \mathrm{M} \mathrm{HCl} / \mathrm{MeOH}$ [at $85{ }^{\circ} \mathrm{C}$ for $24 \mathrm{~h}$; inositol $(10 \mu \mathrm{g})$ as internal standard] followed by trisil reagent $(1,1,1,3,3,3$-hexamethyldisilazane + trimethylchlorosilane + pyridine, 3:1:9) derivatization using the Sylon HTP kit (Supelco; Sigma Aldrich) [53]. The monosugars were separated on a J\&W DB-5MS column (30 m length, $0.25 \mathrm{~mm}$ diameter, $0.25 \mu \mathrm{m}$ film thickness) (Agilent Technologies) and determined using GC-MS (7890A/5975C; Agilent Technologies).

\section{Analysis of total glucan content by high-performance anion-exchange chromatography}

Dry wood powder (0.1-0.5 mm particle size, $100 \mathrm{mg}$ after moisture analysis using HG63 moisture analyzer, Mettler Toledo HG63, Greifensee, Switzerland) was hydrolyzed with sulfuric acid $[3 \mathrm{~mL}, 72 \%(\mathrm{w} / \mathrm{w})]$ for $1 \mathrm{~h}$ at $30{ }^{\circ} \mathrm{C}$. The reaction mixture was diluted to $2.5 \%$ sulfuric acid using deionized water and was autoclaved for $1 \mathrm{~h}$ at $120^{\circ} \mathrm{C}$ [54]. After centrifugation $(14,000 \mathrm{~g}$ for $20 \mathrm{~min})$, the supernatant was collected and analyzed with respect to monosaccharide content using the ICS-3000 (Dionex, Sunnyvale, CA, USA) for greenhouse-grown plant samples and ICS5000 (Dionex) for field-grown plant samples, following the method described by Gandla et al. [55] and Wang et al. [56]. For the analysis of greenhouse-grown trees, three experimental replicates from the pool of 3-5 biological replicates per line and 5 replicates from the pools of 33 biological replicates of WT samples were used. For the analysis of field-grown trees, $3-5$ biological replicates per line and 8 biological replicates of the WT were used.

\section{Pretreatment, enzymatic saccharification, and analysis of reaction mixtures}

Dry and sieved wood powder $(0.1-0.5 \mathrm{~mm}$ particle size, $50 \mathrm{mg}$ after moisture analysis using the HG63 moisture analyzer) was used for enzymatic saccharification with or without hydrothermal pretreatment with sulfuric acid. For the greenhouse-grown trees, each analysis included 3-5 biological replicates for each of the transgenic lines (each replicate representing wood collected from one aspen tree) and five biological replicates for the WT (each replicate representing wood pooled from 2-3 aspen trees). For the field-grown trees, each analysis included 3-5 biological replicates per line and 8 biological replicates for the WT. Pretreatment was performed using an Initiator single-mode microwave instrument (Biotage, Uppsala, Sweden) as previously described in Gandla et al. [55]). Enzymatic saccharification of samples from greenhouse-grown trees was performed using a mixture of liquid enzyme preparations (Celluclast 1.5L and Novozyme 188 ) as previously described in Gandla et al. [55]. Reaction mixtures were incubated at $45^{\circ} \mathrm{C}$ for $72 \mathrm{~h}$. Samples for analysis of sugars were withdrawn after $2 \mathrm{~h}$ (GPR, glucose production rate) and after $72 \mathrm{~h}$ (sugar yields). Enzymatic saccharification of wood powder from field-grown trees was performed similarly, but using $5 \mathrm{mg}$ of the liquid enzyme preparation Cellic CTec-2 (obtained from Sigma-Aldrich, St. Louis, MO, USA). The monosaccharide concentrations [Arabinose (Ara), Galactose (Gal), Glucose (Glu), Xylose (Xyl), and Mannose (Man)] in the pretreatment liquids and in the samples taken after $72 \mathrm{~h}$ were determined using an HPAEC system with pulsed amperometric detection (Ion Chromatography System ICS-3000 for greenhouse-grown plant samples, and ICS5000 for field grown) following the procedure described by Gandla et al. [55] and Wang et al. [56]. The glucose production rate after $2 \mathrm{~h}$ of enzymatic saccharification was determined using an Accu-Chek ${ }^{\circledR}$ Aviva glucometer (Roche Diagnostics Scandinavia AB, Bromma, Sweden) as previously described by Gandla et al. $[55,57]$.

\section{OnPLS analysis}

Multivariate data obtained from transcriptomics, proteomics, Py-GC/MS, UHPLC-MS, and GC-MS platforms were integrated using OnPLS following the procedures described by Obudulu et al. [29]. WT data set values were used as internal reference. Data set values from transgenic lines were combined into one dataset and normalized by subtracting the average WT value from the value of each data point of transgenics and dividing by the standard deviation (SD) of the WT. A significance level corresponding to $\mid p($ CORR $) \mid \geq 0.5$ was used as cut-off value to identify statistically significant variation between transgenic lines and WT [58-62]. $p$ (CORR) stands for the correlation of $p$ (weight of each trait within the model) with the modeled class designation between values from 0 to $( \pm) 1$.

\section{Field trials}

Field trials with the transgenic lines were conducted in a location in Våxtorp in Southern Sweden (GPS coordinates as registered at Jordbruksverket system RT90: X 1,331,589, Y 6,257,832; Våxtorp Plant nursery according 
to Google Maps $56^{\circ} 25^{\prime} 18.6^{\prime \prime} \mathrm{N} 13^{\circ} 04^{\prime} 37.9^{\prime \prime}$ E) during five growing seasons. The trial included eight trees for each of four different transgenic lines $(1,2,3$, and 4$)$ and 147 WT (T89) trees. The trees were multiplied in tissue culture, and transplanted outdoors in Umeå during the summer 2011. After this period, which aimed at hardening the trees to outdoor conditions, the trees were transferred and planted in Våxtorp in the beginning of August 2011. The trees were planted randomly in eight different blocks. First measurement of the trees was conducted in October, 2011, followed by measurement of height and diameter twice a year both in the beginning and at the end of the growing season. Final measurements of height and diameter as well as material harvesting took place in August, 2016. The trees experienced severe drought stress during summer 2016, and therefore the growth measurements done in June 2016 were used as the final results of the whole trial. Damaged trees were excluded from analysis. A filter with a minimum criterion of performance were used to filter away the most damaged plants. Only trees that performed well in the filtration process were included in the analyses of tree height and diameter according to the criteria of having minimum $10 \mathrm{~cm}$ height increase during each growing season and a maximum of $5 \mathrm{~cm}$ growth reduction between consecutive measurements. After filtering, the average seasonal height increase varied between 26 and $49 \mathrm{~cm}$ in all trees of this trial during the four seasons of 2012-2015.

At the end of the field trial, a subset of the trees was harvested for the analyses of total biomass, wood density, wood chemistry and saccharification on the basis of having stem volume at harvest closest to the mean of the genotype. Five individuals were selected for transgenic lines 2-4, including the individual closest to the average and two both above and below the average in stem volume. For transgenic line 1, only three individuals were included since the rest did not pass the above-mentioned filtering criteria. For the wild type, 19 individuals were selected, including the individual closest to the average, and nine below as well as nine above the average in volume. Stem volume was calculated on the basis of the stem diameter and height considering the shape of the stem as a cone. For measurements of biomass production and wood density, the shoots of the current year were discarded. The fresh weight of the remaining part of the stem was measured. From the remaining stem a $5 \mathrm{~cm}$ piece was collected from the top of the stem and the bottom of the stem for density measurements by a waterreplacement method. The dry weight of the $5 \mathrm{~cm}$ pieces was used to calculate total dry weight of the stem.

\section{Statistical analysis}

Data presented in figures and tables were analyzed using the two-tailed Student's $t$-test function in Microsoft Excel 2016 and independent sample $t$-test in IBM SPSS ${ }^{\circledR}$ Statistics software using homoscedastic/equal variance to compare each individual transgenic line with the WT. Asterisks indicate significant differences from the WT at $p \leq 5 \%\left({ }^{*}\right)$, and $\left.p \leq 0.1 \%{ }^{(* *)}\right)$ according to Student's $t$-test.

\section{Supplementary Information}

The online version contains supplementary material available at https://doi. org/10.1186/s13068-021-01895-0.

\begin{abstract}
Additional file 1: Fig. S1. Correlation matrix plot of data obtained from five platforms; GC-MS, LC-MS, Py-GC/MS, Proteomics, and Transcriptomics. Table S1. Monosaccharide composition of wood from wild-type (WT) and PttVAP27-17 overexpression lines of greenhouse-grown trees. Table S2. Relative abundance of metabolites identified by Pyrolysis-GC/ MS analysis of wild-type and transgenic PttVAP27-17 overexpression lines grown in the greenhouse. Table S3. LC-MS metabolomic analysis of wildtype and PttVAP27-17 overexpression lines of greenhouse-grown trees. Table S4. GC-MS metabolomic analysis of wild-type and PttVAP27-17 overexpression lines of greenhouse-grown trees. Table S5. RNAseq analysis of wild-type and PttVAP27-17 overexpression lines of greenhousegrown trees. Table S6. List of all peptides identified in the proteomic study. Table S7. List of all proteins identified in the proteomic study. Table S8. Genes co-expressed with PttVAP27-17. Table S9. Gene ontology (GO) analysis of transcripts (using tool REVIGO from Popgenie homepage popgenie.org) with statistically significant changes in the PttVAP27-17 overexpressing transgenic lines compared to the wild type of greenhouse-grown trees. Table S10. Gene ontology (GO) analysis of all proteins with statistically significant changes in the PtIVAP27-17 overexpressing transgenic lines compared to the wild type of greenhouse-grown trees. Table S11. (a) Overexpression of PttVAP27-17 affects sugar yields of greenhouse-grown trees. (b) Overexpression of PttVAP27-17 affects sugar yields of field-grown trees.
\end{abstract}

\section{Acknowledgements}

The authors thank Junko Takahashi-Schmidt, Anna Petterle and Veronica Bourquin for providing technical help, and the Biopolymer Analytical Platform (BAP, KBC Chemical-Biological Centre, Umeå, Sweden), supported by Bio4Energy and TC4F.

\section{Authors' contributions}

HT designed the study with assistance from MH, TRH, TM, GW, LJJ, and JT. LJ, TM, JT, TRH, GW, and HT supervised the experiments. MLG coordinated the various analyses, and performed the saccharification and monosaccharide assays. NM performed the RNAseq analysis. TS and JT performed the OnPLS analysis. $O O$ performed the metabolomic and proteomic analyses. JB processed the proteomic data. SE assisted in data analyses and interpretation. LM and $\mathrm{MH}$ performed field trials and provided phenotypic data for field-grown trees. INA performed the UHPLC-MS metabolite identification. TM processed the UHPLC-MS data. MLG, HT, and LJJ wrote the manuscript with contributions from all co-authors. All authors read and approved the final manuscript.

\section{Funding}

Open access funding provided by Swedish University of Agricultural Sciences. This research was funded by the Swedish Research Council FORMAS (2322009-1698), the Swedish Foundation for Strategic Research (RBP14-0011), the Swedish Governmental Agency for Innovation Systems Vinnova (2015-02290), the KAW Foundation (2016-0341), the strategic research environment Bio4Energy, and the Swedish Energy Agency (P47516-1). 


\section{Availability of data and materials}

The metabolomic data are deposited to the EMBL-EBI MetaboLights database (https://doi.org/10.1093/nar/gks1004. PubMed PMID: 23109552) with the identifier MTBLS628. The complete dataset can be accessed here: https:// www.ebi.ac.uk/metabolights/MTBLS628.

The transcriptomic data of the WT samples (accession PRJEB21452) and the transgenic samples (Accession PRJEB33910) are deposited at the European Nucleotide Archive.

The mass spectrometry proteomics data have been deposited to the ProteomeXchange Consortium via the PRIDE [63] partner repository with the dataset identifier PXD023826.

\section{Ethics approval and consent to participate}

Not applicable.

\section{Consent for publication}

Not applicable.

\section{Competing interests}

A patent application (WO2016108750) for using the polypeptide corresponding to VAP27-17 (Potri.019G116400) to improve growth properties has been filed by SweTree Technologies with LJJ and MLG as inventors. HT, TM, JT, and GW are members of the holding company Woodheads $A B$, which is a part-owner of SweTree Technologies. MH and LM are employees of SweTree Technologies. SweTree technologies provided the transgenic material and the field trial data, but did not participate in the planning or execution of the greenhouse experiments or presentation/interpretation of the experimental data for this manuscript.

\section{Author details}

${ }^{1}$ Department of Chemistry, Umeå University, 901 87, Umeå, Sweden. ${ }^{2}$ Umeå Plant Science Centre, Department of Plant Physiology, Umeå University, 90187 Umeå, Sweden. ${ }^{3}$ Umeå Plant Science Centre, Department of Forest Genetics and Plant Physiology, Swedish University of Agricultural Sciences, 90183 Umeå, Sweden. ${ }^{4}$ SweTree Technologies, PO Box 7981, 90719 Umeå, Sweden. ${ }^{5}$ Present Address: Faculty of Chemistry, Biotechnology and Food Science, Norwegian University of Life Sciences, 1432 Ås, Norway. ${ }^{6}$ Computational Life Science Cluster (CLiC), Department of Chemistry, Umeå University, Umeå, Sweden. ${ }^{7}$ Present Address: Department of Microbiology and Immunology, Institute of Biomedicine, University of Gothenburg, 40530 Gothenburg, Sweden. ${ }^{8}$ Present Address: Umeå Plant Science Centre, Department of Forest Genetics and Plant Physiology, Swedish University of Agricultural Sciences, 901 83 Umeå, Sweden

Received: 23 October 2020 Accepted: 4 February 2021

Published online: 16 February 2021

\section{References}

1. McCann MC, Carpita NC. Biomass recalcitrance: a multi-scale, multi-factor, and conversion-specific property. J Exp Biol. 2015;66:4109-18.

2. Jönsson $\sqcup$, Martín C. Pretreatment of lignocellulose: formation of inhibitory by-products and strategies for minimizing their effects. Bioresour Technol. 2016;199:103-12.

3. Arantes $V$, Saddler JN. Access to cellulose limits the efficiency of enzymatic hydrolysis: the role of amorphogenesis. Biotechnol Biofuels. 2010;3:4.

4. Chundawat SPS, Beckham GT, Himmel ME, Dale BE. Deconstruction of lignocellulosic biomass to fuels and chemicals. Annu Rev Chem Biomol Eng. 2011;2:121-45.

5. Ohtani M, Ramachandran V, Tokumoto T, Takebayashi A, Ihara A, Matsumoto T, Hiroyama R, Nishikubo N, Demura T. Identification of novel factors that increase enzymatic saccharification efficiency in Arabidopsis wood cells. Plant Biotechnol. 2017;34:203-6.

6. Weighill DA, Jones P, Shah M, Ranjan P, Muchero W, Schmutz J, Sreedasyam A, et al. Pleiotropic and epistatic network-based discovery: integrated networks for target gene discovery. Front Energy Res. 2018;6:30.

7. Halpin C. Lignin engineering to improve saccharification and digestibility in grasses. Curr Opin Biotechnol. 2019;56:223-9.
8. Taylor G. Populus: Arabidopsis for forestry. Do we need a model tree? Ann Bot Lond. 2002;90:681-9.

9. Tuskan GA, Difazio S, Jansson S, Bohlmann J, Grigoriev I, Hellsten U, Putnam $N$, et al. The genome of Black cottonwood, Populustrichocarpa (Torr. \& Gray). Science. 2006;313:1596-604.

10. The AspWood database. http://aspwood.popgenie.org.

11. Lin Y-C, Wang J, Delhomme N, Schiffthaler B, Sundström G, Zuccolo A, Nystedt B, et al. Functional and evolutionary genomic inferences in Populus through genome and population sequencing of American and European aspen. Proc Natl Acad Sci USA. 2018;115:E10970-8.

12. Wilkerson CG, Mansfield SD, Lu F, Withers S, Park J-Y, Karlen SD, GonzalesVigil $\mathrm{E}$, et al. Monolignol ferulate transferase introduces chemically labile linkages into the lignin backbone. Science. 2014;344:90-3.

13. Biswal AK, Hao Z, Pattathil S, Yang X, Winkeler K, Collins C, Mohanty SS, et al. Downregulation of GAUT12 in Populus deltoides by RNA silencing results in reduced recalcitrance, increased growth and reduced xylan and pectin in a woody biofuel feedstock. Biotechnol Biofuels. 2015;12:41.

14. Cai Y, Zhang K, Kim H, Hou G, Zhang X, Yang H, Feng H, et al. Enhancing digestibility and ethanol yield of Populus wood via expression of an engineered monolignol 4-O-methyltransferase. Nat Commun. 2016;7:11989.

15. Biswal AK, Atmodjo MA, Li M, Baxter HL, Yoo CG, Pu Y, Lee Y-C, et al. Sugar release and growth of biofuel crops are improved by downregulation of pectin biosynthesis. Nat Biotechnol. 2018;36:249-57.

16. Wagner A, Donaldson L, Kim H, Phillips L, Flint H, Steward D, Torr K, et al. Suppression of 4-coumarate-CoA ligase in the coniferous gymnosperm Pinus radiata. Plant Physiol. 2009;149:370-83.

17. Voelker SL, Lachenbruch B, Meinzer FC, Kitin P, Strauss SH. Transgenic poplars with reduced lignin show impaired xylem conductivity, growth efficiency and survival. Plant Cell Environ. 2011;34:655-68.

18. Biswal AK, Soeno K, Gandla ML, Immerzeel P, Pattathil S, Lucenius J, Serimaa $R$, et al. Aspen pectate lyase PtxtPL1-27 mobilizes matrix polysaccharides from woody tissues and improves saccharification yield. Biotechnol Biofuels. 2014:7:11.

19. Van Acker R, Leplé J-C, Aerts D, Storme V, Goeminne G, Ivens B, Légée $F$, et al. Improved saccharification and ethanol yield from field-grown transgenic poplar deficient in cinnamoyl-CoA reductase. Proc Natl Acad Sci USA. 2014;111:845-50.

20. Unda F, Kim H, Ralph J, Mansfield SD. Altering carbon allocation in hybrid poplar (Populus alba $\times$ grandidentata) impacts cell wall growth and development. Plant Biotechnol J. 2017;15:865-78.

21. Saleme MLS, Cesarino I, Vargas L, Kim H, Vanholme R, Goeminne G, Van Acker $\mathrm{R}$, et al. Silencing Caffeoyl shikimate esterase affects lignification and improves saccharification in poplar. Plant Physiol. 2017;175:1040-57.

22. Escamez S, Gandla ML, Derba-Maceluch M, Lundqvist S-O, Mellerowicz EJ, Jönsson $\mathrm{L}$, Tuominen $\mathrm{H}$. A collection of genetically engineered Populus trees reveals wood biomass traits that predict glucose yield from enzymatic hydrolysis. Sci Rep. 2017;7:15798.

23. Pinto RC, Gerber L, Eliasson M, Sundberg B, Trygg J. Strategy for minimizing between-study variation of large-scale phenotypic experiments using multivariate analysis. Anal Chem. 2012;84:8675-8.

24. Alpy F, Rousseau A, Schwab Y, Legueux F, Stoll I, Wendling C, Spiegelhalter $C$, et al. STARD3 or STARD3NL and VAP form a novel molecular tether between late endosomes and the ER. J Cell Sci. 2013;126:5500-12.

25. Wang P, Richardson C, Hawkins TJ, Sparkes I, Hawes C, Hussey PJ. Plant VAP27 proteins: domain characterization, intracellular localization and role in plant development. New Phytol. 2016;210:1311-26.

26. Van Bel M, Diels T, Vancaester E, Kreft K, Botzki A, Van de Peer Y, Coppens F, et al. PLAZA 4.0: an integrative resource for functional, evolutionary and comparative plant genomics. Nucleic Acids Res. 2018;46(D1):D1190-6.

27. Combet C, Blanchet C, Geourjon C, Delage G. Network protein sequence analysis. Trends Biochem Sci. 2000;25:147-50.

28. Käll L, Anders Krogh A, Sonnhammer ELL. Advantages of combined transmembrane topology and signal peptide prediction-the Phobius web server. Nucleic Acids Res. 2007:35:W429-32.

29. Obudulu O, Mähler N, Skotare T, Bygdell J, Abreu IN, Ahnlund M, Gandla $\mathrm{ML}$, et al. A multi-omics approach reveals function of Secretory CarrierAssociated Membrane Proteins in wood formation of Populus trees. BMC Genomics. 2018;19:11.

30. Löfstedt T, Trygg J. OnPLS — a novel multiblock method for the modelling of predictive and orthogonal variation. J Chemometr. 2011;25:441-55. 
31. Löfstedt T, Hanafi M, Mazerolles G, Trygg J. OnPLS path modelling. Chemometr Intell Lab Syst. 2012;118:139-49.

32. Trygg J. O2-PLS for qualitative and quantitative analysis in multivariate calibration. J Chemometr. 2002;16:283-93.

33. Trygg J, Wold S. O2-PLS, a two-block ( $\mathrm{X} \pm \mathrm{Y}$ ) latent variable regression (LVR) method with an integral OSC ${ }^{\circledR}$ Iter $^{2}$. J Chemometr. 2003;17:53-64.

34. Skotare T, Sjögren R, Surowiec I, Nilsson D, Trygg J. Visualization of descriptive multiblock analysis. J Chemometr. 2020;34:e3071.

35. The Popgenie database. http://popgenie.org.

36. Ratke C, Terebieniec BK, Winestrand S, Derba-Maceluch M, Grahn T, Schiffthaler B, Ulvcrona T, et al. Downregulating aspen xylan biosynthetic GT43 genes in developing wood stimulates growth via reprograming of the transcriptome. New Phytol. 2018;219:230-45.

37. Voelker SL, Lachenbruch B, Meinzer FC, Jourdes M, Ki C, Patten AM, Davin $L B$, et al. Antisense down-regulation of $4 C L$ expression alters lignification, tree growth, and saccharification potential of field-grown poplar. Plant Physiol. 2010;154:874-86.

38. Xiang Z, Sen SK, Roy A, Min D, Savithri D, Jameel H, Chiang V, Chang H-M. Wood characteristics and enzymatic saccharification efficiency of field-grown transgenic black cottonwood with altered lignin content and structure. Cellulose. 2015;22:683-93.

39. Xiang Z, Sen SK, Roy A, Min D, Savithri D, Lu F, Jameel H, Chiang V, Chang $H$-M. Field-grown transgenic hybrid poplar with modified lignin biosynthesis to improve enzymatic saccharification efficiency. ACS Sustain Chem Eng. 2017:5:2407-14.

40. Wang P, Hawkins TJ, Richardson C, Cummins I, Deeks MJ, Sparkes I, Hawes C, et al. The plant cytoskeleton, NET3C and VAP27 mediate the link between the plasma membrane and endoplasmic reticulum. Curr Biol. 2014;24:1397-405.

41. Stefano G, Renna L, Wormsbaecher C, Gamble J, Zienkiewicz K, Brandizzi F. Plant endocytosis requires the ER membrane anchored proteins VAP27-1 and VAP27-3. Cell Rep. 2018;23:2299-307.

42. Nilsson O, Aldén T, Sitbon F, Little CHA, Chalupa V, Sandberg G, Olsson $\mathrm{O}$. Spatial pattern of cauliflower mosaic virus $35 \mathrm{~S}$ promoter-luciferase expression in transgenic hybrid aspen trees monitored by enzymatic assay and non-destructive imaging. Transgenic Res. 1992;1:209-20.

43. Whelan S, Goldman N. A general empirical model of protein evolution derived from multiple protein families using a maximum-likelihood approach. Mol Biol Evol. 2001;18:691-9.

44. Schliep PK. phangorn: phylogenetic analysis in R. Bioinformatics. 2011;27:592-3.

45. Yu G, Smith DK, Zhu H, Guan Y, Lam TT-Y. GGTREE: an R package for visualization and annotation of phylogenetic trees with their covariates and other associated data. Methods Ecol Evol. 2017;8:28-36.

46. Wickham H. ggplot2 elegant graphics for data analysis (use R!), vol. 2. New York: Springer; 2016

47. Jones P, Binns D, Chang H-Y, Fraser M, Li W, McAnulla C, McWilliam H, et al. InterProScan 5: genome-scale protein function classification. Bioinformatics. 2014;30:1236-40.

48. Dobin A, Davis CA, Schlesinger F, Drenkow J, Zaleski C, Jha S, Batut P, et al. STAR: ultrafast universal RNA-seq aligner. Bioinformatics. 2013;29:15-21.

49. Love MI, Huber W, Anders S. Moderated estimation of fold change and dispersion for RNA-seq data with DESeq2. Genome Biol. 2014;15:550.

50. Srivastava V, Obudulu O, Bygdell J, Löfstedt T, Rydén P, Nilsson R, Ahnlund $M$, et al. OnPLS integration of transcriptomic, proteomic and metabolomic data shows multi-level oxidative stress responses in the cambium of transgenic hipl-superoxide dismutase Populus plants. BMC Genomics. 2013;14:893.

51. Jonsson P, Johansson Al, Gullberg J, Trygg J, Grung B, Marklund S, Sjöström $M$, et al. High-throughput data analysis for detecting and identifying differences between samples in GC/MS-based metabolomic analyses. Anal Chem. 2005;77:5635-42.

52. Gerber L, Öhman D, Kumar M, Ranocha P, Goffner D, Sundberg B. High-throughput microanalysis of large lignocellulosic sample sets by pyrolysis-gas chromatography/mass spectrometry. Physiol Plant. 2016;156:127-38.

53. Sweeley CC, Bentley R, Makita M, Wells WW. Gas-liquid chromatography of trimethylsilyl derivatives of sugars and related substances. J Am Chem Soc. 1963;85:2497-507.

54. Suzuki M, Sakamoto R, Aoyagi T. Rapid carbohydrate analysis of wood pulps by ion chromatography. TAPPI J. 1995;78:174-7.

55. Gandla ML, Derba-Maceluch M, Liu X, Gerber L, Master ER, Mellerowicz EJ, Jönsson LJ. Expression of a fungal glucuronoyl esterase in Populus: effects on wood properties and saccharification efficiency. Phytochemistry. 2015;112:210-20.

56. Wang Z, Winestrand S, Gillgren T, Jönsson LJ. Chemical and structural factors influencing enzymatic saccharification of wood from aspen, birch and spruce. Biomass Bioenergy. 2018;109:125-34.

57. Gandla ML, Martin C, Jönsson L. Analytical enzymatic saccharification of lignocellulosic biomass for conversion to biofuels and bio-based chemicals. Energies. 2018;11:2936.

58. Wiklund S, Johansson E, Sjöström L, Mellerowicz EJ, Edlund U, Shockcor JP, Gottfries J, et al. Visualization of GC/TOF-MS-based metabolomics data for identification of biochemically interesting compounds using OPLS class models. Anal Chem. 2008;80:115-22.

59. Tulipani S, Llorach R, Jáuregui O, López-Uriarte P, Garcia-Aloy M, Bullo M, Salas-Salvadó J, et al. Metabolomics unveils urinary changes in subjects with metabolic syndrome following 12-week nut consumption. J Proteome Res. 2011;10:5047-58.

60. Llorach R, Urpi-Sarda M, Jauregui O, Monagas M, Andres-Lacueva C. An LC-MS-based metabolomics approach for exploring urinary metabolome modifications after cocoa consumption. J Proteome Res. 2009;8:5060-8.

61. Llorach R, Garrido I, Monagas M, Urpi-Sarda M, Tulipani S, Bartolome B, Andres-Lacueva C. Metabolomics study of human urinary metabolome modifications after intake of almond (Prunus dulcis (Mill.) D.A. Webb) skin polyphenols. J Proteome Res. 2010;9:5859-67.

62. Llorach R, Medina S, García-Viguera C, Zafrilla P, Abellán J, Jauregui O, Tomás-Barberán FA, et al. Discovery of human urinary biomarkers of aronia-citrus juice intake by HPLC-q-TOF-based metabolomic approach. Electrophoresis. 2014;35:1599-606.

63. Perez-Riverol Y, Csordas A, Bai J, Bernal-Llinares M, Hewapathirana S, Kundu DJ, Inuganti A, et al. The PRIDE database and related tools and resources in 2019: improving support for quantification data. Nucleic Acids Res. 2019;47(D1):D442-50.

\section{Publisher's Note}

Springer Nature remains neutral with regard to jurisdictional claims in published maps and institutional affiliations.

Ready to submit your research? Choose BMC and benefit from:

- fast, convenient online submission

- thorough peer review by experienced researchers in your field

- rapid publication on acceptance

- support for research data, including large and complex data types

- gold Open Access which fosters wider collaboration and increased citations

- maximum visibility for your research: over $100 \mathrm{M}$ website views per year

At BMC, research is always in progress.

Learn more biomedcentral.com/submissions 